\title{
APRENDIZADO E COMPETÊNCIAS, UMA DIFÍCIL RELAÇÃO ENTRE CONSTRUIR O CONHECIMENTO E PARCOS INVESTIMENTOS EM RECURSOS PARA A EDUCAÇÃO.
}

\author{
S. L. S. Moura ${ }^{1 *}$; J. P. Monteiro²; R. A. Moura² \\ 1 Diretoria do Ensino região de Taubaté Praça 8 de maio, 28, Centro, \\ Taubaté/SP CEP: 12030-200, Brasil. Telefone: (12) 3625-0710 \\ 2 Faculdade de Tecnologia de São José dos Campos - Professor Jessen Vidal \\ Av. Cesare Mansueto Giulio Lattes, 1350 - Eugênio de Melo, São José dos \\ Campos/SP, CEP: 12247-014, Brasil. Telefone: (12) 3905-2423 \\ *silvialosamo@uol.com.br
}

\begin{abstract}
RESUMO: A tecnologia tende a distanciar-se da educação profissional pública, pois cortes no orçamento privam a atualização dos recursos para aprendizagem. Assim, este artigo objetiva revisar bibliograficamente e demonstrar que o aprendizado das gerações baby boomer, " $x$ " e " $y$ ", pouco se atualizaram na dicotomia acadêmico-profissional. O método utilizado contou com uma revisão bibliométrica e uma pesquisa com 331 indivíduos de ambos os sexos, com idade de 20 até 60 anos portadores no mínimo do diploma do ensino médio. O resultado demonstrou que há falta de planejamento e atualização dos recursos para ensinar, o que compromete o conhecimento e a habilidade técnica dos alunos. Conclui-se que quando há uma lacuna vaga, algo a preencherá, ou seja, onde faltou à competência tecnológica a mesma foi preenchida com as competências emocional e social, deduzindo que o egresso precisa desenvolver a competência sociabilidade para que seja aceito pelo time de trabalho.
\end{abstract}

PALAVRAS-CHAVE: baby boomer; geração "x"; geração "y".

ABSTRACT: The technology tends to distance itself from public vocational education, because of budget cuts that deprive the resource of learning resources. This article aims to review bibliographically and demonstrate that the learning of the baby boomer generations, "x" and "y", have not been updated in the academic-professional dichotomy. The method used included a bibliometric review and a survey of 331 individuals of both sexes, aged 20 to 60 years with a minimum of high school diploma. The result showed that there is a lack of planning and updating of resources to teach, which compromises students' knowledge and technical ability. It is concluded that when there is a vacant gap, something will fill it, that is, where it lacked the technological competence, it was be filled with emotional and social skills, showing that the student needs to develop sociability' competence in order to be accepted by the teamwork.

KEYWORDS: baby boomer; generation " $x$ "; generation " $y$ ".

\section{INTRODUÇÃO}

Este trabalho traz uma proposta voltada para educação pública contemporânea, alertando que a instituição escolar deve se preocupar em focar nos discentes e não mais só nos docentes, pois em uma primeira análise, o grande diferencial responsável pela retenção escolar será a empregabilidade e em segunda análise, a evasão pela insatisfação do que se aprende. 
Uma abordagem da política educacional para gerações baby boomer, "x" e "y e futuras", se faz necessário inclusive na égide da Lei n. 9.394/1996, como norma reguladora da Educação no Brasil com seus avanços e desafios, e que vem impactando na história da Educação desde a sua aprovação em 1996, definindo no seu artigo $1^{\circ}$ que a Educação abrangerá os processos formativos que se desenvolvem na vida familiar, na convivência humana, no trabalho e disciplinando a educação escolar, que se vincula ao mundo do trabalho, a prática social (BRASIL, 2019).

No mês de abril (2019), governo anunciou o congelamento de $\mathrm{R} \$ 1,7$ bi dos gastos das universidades, de um total de $\mathrm{R} \$ 49,6$ bi, considerando $24,84 \%$ dos gastos não obrigatórios, conhecidos como discricionários e 3,43\% do orçamento total das federais, que na visão da associação dos reitores das universidades federais (ANDIFES) é o maior contingenciamento desde 2014. O corte no orçamento afetou as despesas correntes para manter o funcionamento como contas de luz e de água, as bolsas acadêmicas, insumos de pesquisas e investimentos para compra de equipamentos (O GLOBO, 2019), conforme pode ser verificado no Gráfico 1.

Gráfico 1. Corte do orçamento educacional

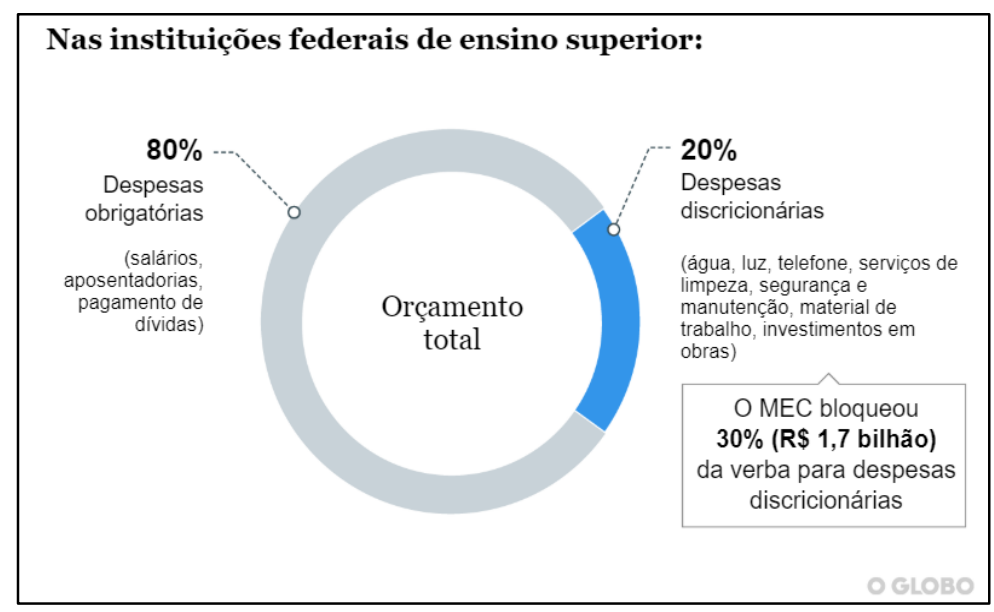

\subsection{Gerações baby boomer e " $\mathrm{x}$ "}

Para a geração "Baby Boomer" que surgiu pós-guerra, sempre vigorou a ideia de que se deve poupar e guardar tudo, inclusive o conhecimento, pois isto faria a diferença em épocas duras e de escassez. A geração "x" sofreu forte influência da geração "baby boomer" e estudaram de maneira para que aprendessem e se tornassem "experts". Predominantes até os anos 70, essa geração aprendeu que guardar, poupar e ter um objetivo na vida era o ideal. Tal pensamento definiam as suas competências e caráter e assim, muitos ficam por mais de três décadas trabalhando em uma mesma empresa, comprometidos com o lema "vestir a camisa" pois para essa geração ter um crachá de uma instituição ou organização desejada pela coletividade, era um objetivo e muitas vezes usada como sobrenome (CONGER, 1998).

\subsection{Gerações "y e futuras"}

A geração “y”, famosa por seu imediatismo e não se preocupar em poupar ou guardar, mas sim compartilhar, é reconhecido jocosamente como geração "nem-nem", nem estuda e nem trabalha, é o principal foco deste trabalho, haja vista que respeitar hierarquia não é de sua natureza, ou seja, se o plano político pedagógico atender as expectativas desta geração, os alunos nada reclamaram, mas se não atender, sem qualquer hesitação usaram os meios sociais para seu manifesto e repúdio (LOIOLA, 2009; OLIVEIRA, 2009).

A geração "y" particularmente, consegue unir a teoria com sua aplicação, vendo o professor como um canal para sua aprendizagem, porém não o único, pois, quase que em ato simultâneo, fará um "tour" global através de sua máquina e acesso tecnológico da "internet" para validar o que 


\section{ISSN $2447-5378$}

aprendeu. Desse modo, há a união do mundo virtual com o mundo real às vezes limitada por um "layout" atual deficiente, ou melhor, ultrapassado, por faltar recursos físicos como falta de tomadas e/ou fontes de energia para recarregar os aparelhos (ENGELMANN, 2009).

\section{REVISÃO BIBLIOGRÁFICA}

A abordagem da política educacional para as diferentes gerações, considerando que a geração baby boomer já quase não ocupa mais os bancos escolares, salvo uma quantidade mínima que busca especializações, encontra na Lei de Diretrizes e Bases da educação nacional (LDB) uma retrospectiva pela história da educação, no Brasil, considerando a dicotomia que a LDB pode ser considerada, ao mesmo tempo, um avanço e um desafio (VELOSO, DUTRA e NAKATA, 2011).

Avanço porque normatizou o sistema escolar nacional e um desafio porque a educação pública se tornou um mecanismo vivo e profissional que frequentemente tem de atingir padrões e metas exigidas por entidades reguladoras e filiadas ao Ministério da Educação e Cultura (MEC). O desafio da LDB é a valorização dos profissionais da educação e a permanência dos alunos na escola com uma qualidade do ensino melhor e atualizada, pois a correta alfabetização precisa ser sincera e profissionalizante, com um ensino médio e acima, preparando e qualificando os indivíduos para atenderem as necessidades do mercado de trabalho (LIMA e ZAGO, 2018).

Nesse viés, um tema importante na literatura tem sido a busca por indicadores comportamentais que distinguem os indivíduos quando estão aprendendo ou não, pois é a maneira mais segura de entender as descobertas da necessidade de se aprender e criar competências que envolvem a síntese estatística da construção do saber (LUCKESI, 2011).

Segundo Resende (2008), competência constitui-se como sendo a capacidade dos colaboradores e das empresas relacionadas ao domínio e à aplicação dos conhecimentos destes, pois cada profissão, cargo ou atividade, requer competências específicas. À medida que surgem novas funções e profissões, novas competências e habilidades podem ser requeridas.

Ainda, de acordo com Resende (2008), com a evolução das práticas de gestão de pessoas por competências, é necessário aprimorar as descrições de cargos, ou seja, os cargos devem conter mais informações a respeito das competências e habilidades requeridas bem como papeis e responsabilidade definidas, como domínio de conhecimento; habilidade profissional e atitude proativa, pois além de saber fazer ou executar, é necessário explicar e dividir com os pares, as melhores práticas e assim surge a competência emocional seguida da social, pois as habilidades são determinadas de acordo com o conhecimento e a atitude, contudo o saber conviver, usar de entendimento e empatia, somente pode ocorrer quando o indivíduo desenvolveu as competências emocional e social.

\subsection{Competências sociais e profissionais e a relação proposta entre elas}

As competências lominger, conseguem demonstrar em suas 67 competências elencadas, tratadas e definidas quais são as competências profissionais que permeiam o mercado de trabalho para direcionar o tipo de qualificação que fazem toda diferença em um mercado, onde os vínculos são precários e susceptíveis de se acabarem com a chegada da terceirização (LOMBARDO e EICHINGER, 2006).

Ainda segundo Lombardo e Eichinger (2006), o conhecimento, habilidade e atitude (CHA), que dizem respeito à forma de desenvolvimento da competência profissional está associada à qualidade de quem é capaz de apreciar e resolver determinado assunto ou realizar determinada tarefa, por ser solicito e sociável, remetendo à ideia de capacidade, soma de conhecimentos ou habilidades com integração e a coordenação da competência são conjuntos de técnicas e sociabilidade que na sua 


\section{ISSN $2447-5378$}

manifestação produzem uma atuação diferenciada, pois a habilidade é a capacidade de transformar conhecimento em ação e a sociabilidade de divulgá-la com respeito, compaixão e pessoalidade.

Uma metanálise sobre competências mais abrangente sobre o comportamento, foi conduzida por De Paulo et. al., (2003), e incluiu análises de 158 comportamentos, com sinais não-verbais, como inquietação, movimentos oculares, alterações posturais, sugestões verbais para uma abordagem comportamental externa, primeiro a variação nos tipos de declarações quando o que quer aprender e segundo, porque os participantes no seu próprio íntimo profissional se conectam ou não ao aprendizado e desempenho em sua vida profissional (ZANOTTO, 2002). Avaliar a eficácia e eficiência de forma contínua a respeito do desempenho dos alunos antes, durante e após a intervenção (LEONARDI e MAYER, 2016) e repetir se necessário visando garantir a meta, é, portanto, a essência do aprendizado (HENKLAIN, CARMO e LOPES JR, 2016) pois haja vista que nas conclusões e procedimento do aprendizado, os indivíduos irão demonstrar resultados para situações análogas, indiretamente indexadas as métricas e no potencial empírico do que aprenderam (HENKLAIN et. al., 2016).

Stein, 1994, apontou que criar um ambiente com recurso tecnológico, compensa de certa forma, a má qualidade no desenvolvimento acadêmico advindas de deficiências ulteriores físicas, sensoriais, mentais e intelectuais. Nesse sentido, ressalta-se o experimento histórico de Sidman (2000) que ensinou a ler um rapaz com necessidade especial quando o mesmo relacionou a fala a uma figura e depois a nomeou. Ao ensinar a ler e a escrever, pode-se ensinar ao indivíduo a identificar prioridades, unidades, técnicas e repertórios, ampliando assim o estímulo de aprender (FARRELL e SERNA, 2011).

Um meio de ensinar é através do emparelhamento com modelos respeitando os discentes que absorvem o aprendizado de maneira, seja pela visão, audição ou toques ou ainda por combinação entre elas, pois, há módulos diferentes e recursos de estudos com atividades de estímulos que incitam e controlam a construção do saber (REIS, SOUZA e ROSE, 2009).

\subsection{Comportamento visual, auditivo e cinestésico.}

Segundo Yong (2013), o cérebro humano é dividido em duas partes, ou seja, em hemisfério esquerdo que é responsável pelo racional, e hemisfério direito, responsável pelo emocional. Suas funções estão relacionadas ao intelecto, ao controle muscular, à regulação interna das funções corporais e aos centros emocionais, cumprindo cada hemisfério uma função específica que acontece na organização neurológica, conforme pode ser visualizado na Figura 1

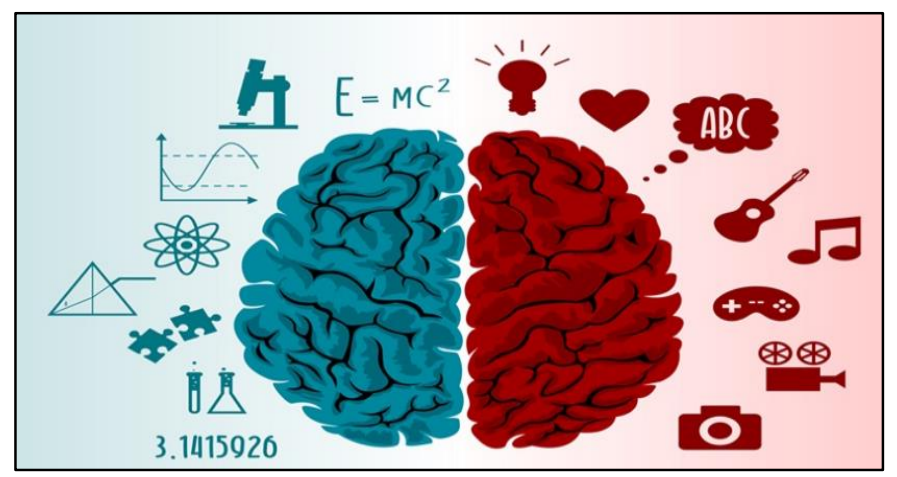

Figura 1. Cérebro dividido em dois hemisférios: racional e emocional

Apesar de atuarem de maneira conjunta, um dos hemisférios é sempre mais predominante que o outro, e cada pessoa tem maior intimidade com um e menos com o outro. De acordo com as diferenças da habilidade profissional e técncias, usa-se cada um dos hemisférios, de modo a formar uma matriz para o aprendizado pela forma visual, auditiva ou cinestésica (YONG, 2013). 
Conforme a neurolinguística, as pessoas reinterpretam conforme sua crença, costumes sentidos e personalidade e as se expressam prevalecendo o canal de aprendizado mais desenvolvido, demonstrado principalmente no convívio social (PEDREIRA, 2014; FUSCO, 2016; GAZOLA, 2015). A Tabela 1 demonstra as particularidades de cada canal de aprendizado.

Tabela 1. Canal de aprendizado: visual, cinestésico e auditivo

\begin{tabular}{|c|c|}
\hline Can & Particularidade e características pessoais \\
\hline & $\begin{array}{l}\text { - Essas pessoas têm um alto nivel de energia; } \\
\text { - Inquietos, observadoras, detalhistas; } \\
\text { - É comum escrever pequenas anotações; } \\
\text { - Precisam de lugares tranquilos para se concentrar; } \\
\text { - São ligados a beleza e estética; } \\
\text { - Falam rapidamente porque as imagens se sucedem em sua mente como um filme; } \\
\text { - Entre o prático e o bonito, a pessoa visual sempre escolherá o bonito; } \\
\text { - Tendem ao perfeccionismo, arrumação e ordem; } \\
\text { - Os visuais precisam que mostrem o que é; } \\
\text { - Não dão valor às palavras e não reagem ao toque contrário a pessoa cinestésica. }\end{array}$ \\
\hline va & $\begin{array}{l}\text { - Expressam seus pensamentos em voz alta; } \\
\text { - Preferem ouvir do que ler; } \\
\text { - São pessoas mais relaxadas, comunicativas e se expressam bem; } \\
\text { - Gostam de conversar e dão detalhe do que ouviram; } \\
\text { - Não valorizam as aparências, mas o bom papo, bom senso e inteligência; } \\
\text { - Equilibradas, prontas para discutir e acreditam na lógica dos argumentos; } \\
\text { - Tom da voz médio, respiração torácica e abdominal; } \\
\text { - Ótima memória para os sons; } \\
\text { - Se incomodam com barulho e vozes estridentes; } \\
\text { - Apreciam músicas com letras bem elaboradas e com mensagem consistente; } \\
\text { - O auditivo precisa ouvir para acreditar. }\end{array}$ \\
\hline & $\begin{array}{l}\text { - Gosta de cozinhar, de esporte e trabalhar ao ar livre; } \\
\text { - Prefere experimentar as coisas antes de se informar sobre elas; } \\
\text { - Apesar de tranquilas, sentem um gosto especial pelas emoções; } \\
\text { - Expram de coisas manuais e experimentar o tato, o gosto e o olfato; } \\
\text { físicos; } \\
\text { - São detalhistas, espontâneas e procuram emoções em primeiro lugar; } \\
\text { - Sujeitos ao sofrimento e todas as experiências são físicas; } \\
\text { - Preferem conforto à beleza e buscam o bem-estar, o prazer e o aconchego: } \\
\text { - Precisa ser abraçado, tocada, beijada para que se sinta amada; } \\
\text { - Prefere roupas velhas e confortáveis, sapatos que não apertam; } \\
\text { - Geralmente nadam, pisam na areia e buscam estar junto da natureza; } \\
\text { - Tom de voz baixo, ritmo lento e respiração abdominal; }\end{array}$ \\
\hline
\end{tabular}

\subsection{Avaliação comportamental do aprendizado}

Para Luckesi (2011), a avaliação do aprendizado é inerente a vida humana e prática social. Avaliar o aprendizado deve ser um processo tranquilo, somatizador e contínuo e que o discente saiba que avaliar o que se aprendeu não é a mesma coisa que um exame. Nesse viés, o processo da diagnose e avaliação deve indicar a qualidade e ter uma finalidade pré-determinada (YONG, 2013).

Os instrumentos de avaliação da aprendizagem devem ser adequados para coletar os dados necessários para pessoalizar o educando e o qual seu tipo de canal de aprendizado para uma compreensão, análise, síntese e aplicação estejam em conformidade com a unidade ensinoaprendizagem planejada e também, que fique claro e compreendido para os alunos, que o processo de reaprendizagem e reforço são sobre o que eles não aprenderam (LUCKESI, 2011).

Para Fachin (2001) o estudo deve oferece atividades com grupamentos humanos em universos populacionais com um referencial teórico, como forma de gerir um processo sistemático de construção do saber ou sua ampliação, enfocando as particularidades do canal de aprendizado e as gerações a qual pertence.

\section{MATERIAIS E MÉTODOS}


O presente estudo baseou-se na análise bibliométrica de artigos sobre educação e seus vieses publicados e revisados entre 1998 e 2019 em periódicos, com o objetivo de caracterizar e analisar seus conhecimentos, além de identificar lacunas para orientar novos estudos científicos na melhoria da educação. Este trabalho contou também com uma pesquisa realizada por meio de três perguntas referentes ao mapa-múndi e divulgada por mídia digital, contando com a resposta de 334 voluntários, de ambos os sexos, faixa etária de 20 até 60 anos, portadores no mínimo, do diploma do ensino médio.

\subsection{Cálculo do número de amostra e margem de erro}

Segundo Triola (2008), como na maioria das vezes é inviável ouvir a opinião de toda uma população ou avaliar todos os produtos de uma linha de montagem, podemos analisar uma amostra e fazer inferências sobre o todo, pois a amostra representa o todo desde que, realizada de forma aleatória. Estatisticamente, há uma relação direta entre proporção da amostra e a margem de erro. $\mathrm{O}$ tamanho da amostra pode ser calculado utilizando a Equação 1.

$$
\mathrm{n}=\frac{N \cdot Z^{2} \cdot p \cdot(1-p)}{(N-1) \cdot \mathrm{e}^{2}+Z^{2} \cdot p \cdot(1-p)}
$$

Onde:

$\mathbf{n}=$ tamanho da amostra;

$\mathbf{N}=$ população;

$\mathbf{Z}=$ é o desvio do valor médio;

$\boldsymbol{p}=$ "rô". Proporção da pesquisa

$\mathbf{e}=$ margem de erro.

Margem de erro representa quantos pontos percentuais às respostas da sua população irão variar em relação às respostas obtidas com a amostra. Quanto menor a margem de erro, mais próximo se estará da resposta exata a um grau de confiança específico (LEVIN, 2004).

Substituindo na equação 1 , tem-se:

$$
\begin{array}{ll}
\checkmark \text { População } & =1950 \text { indivíduos. } \\
\checkmark \text { Tamanho da amostra } & =334 \text { indivíduos. } \\
\checkmark \text { Confiabilidade } & =95 \% . \\
\checkmark \text { Margem de erro } & =4,9 \%
\end{array}
$$

\subsection{Protocolo da pesquisa e suas perguntas}

A Figura 2 objetiva mapear a faixa etária, considerando a faixa etária de 20 a 30 anos são integrantes da geração " $y$ "; de 31 a 49 anos integrantes da geração "x" e acima de 50 anos integrantes da geração "baby boomer".

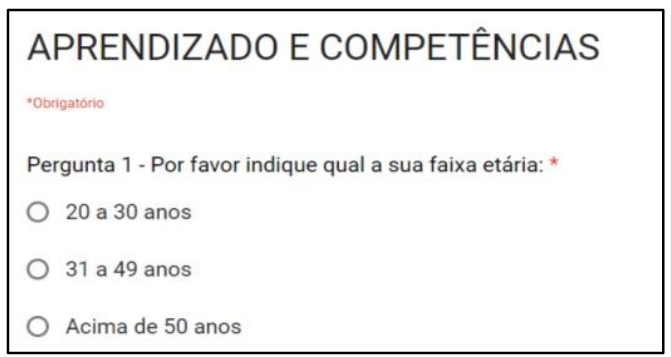

Figura 2. Mapeamento das diferentes gerações.

A Figura 3 visa mapear o modo visual, classe e recursos tecnológicos disponíveis para os alunos, além de demonstrar a intensidade do aprendizado. 


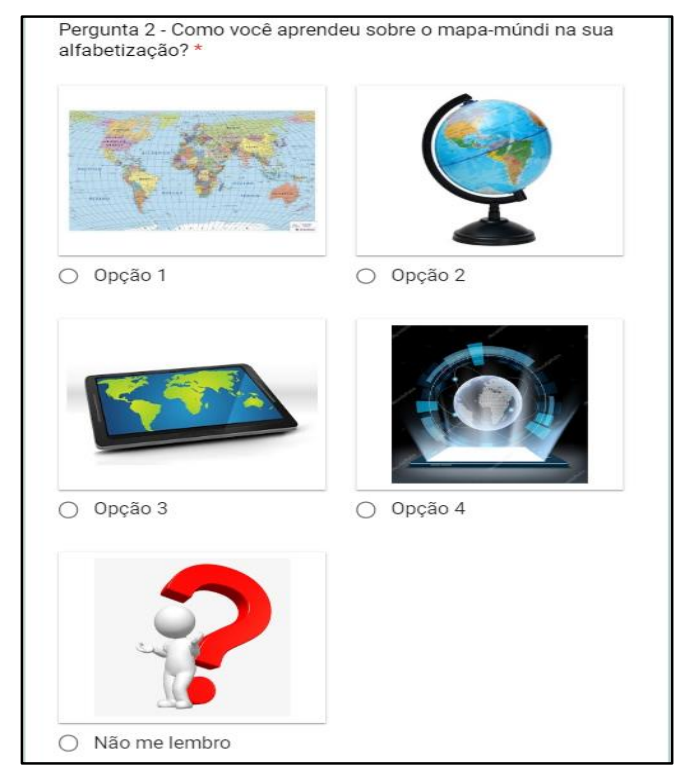

Figura 3. Mapeamento dos recursos tecnológicos disponíveis durante a aprendizagem

A Figura 4 mapeia o estilo de aprendizagem e as relaciona ao tipo de pessoas, isto é, se são visuais, auditivas ou cinestésicas.

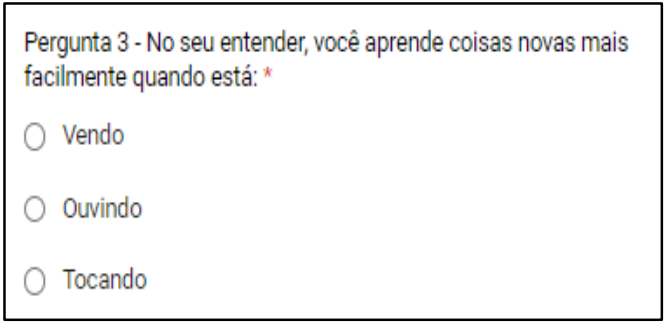

Figura 4. Mapeamento do estilo visual, auditivo e cinestésico de aprendizagem

Assim esse instrumento investigativo, sendo uma pesquisa aleatória estruturada, identificou quais as manifestações e atitudes dos indivíduos e correlaciona com o tema em questão construindo um referencial prático das pessoas pertencentes às diferentes gerações.

\section{RESULTADOS E DISCUSSÕES}

O resultado foi estruturado em duas partes. Uma contemplou aspectos quantitativos da revisão bibliográfica e outro, uma pesquisa para que 334 indivíduos se identificassem a geração que pertencem, percepções e o canal de aprendizagem após responderem três questões.

\subsection{Resultado da revisão bibliográfica}

A revisão bibliográfica identificou que o comportamento dos indivíduos na organização mudou, devido o não investimento nos recursos tecnológicos para aprendizado, principalmente sob a perspectiva técnica-profissional. Assim, surgiu a competência social como compensadora da falta da competência técnica, completando desta forma, a falta do conhecimento e da habilidade técnica, pela sociabilidade de saber trabalhar em time.

Ao se fazer uma análise das respostas obtidas com referencial teórico pesquisado e que caracteriza as gerações é possível considerar que as proposições de questionamentos são relevantes, 


\section{ISSN $2447-5378$}

surge o acrônimo "C.H.A.V.E.S.”, uma palavra formada pela inicial das palavras conhecimento, habilidade, atitude, valores, ética e sociabilidade, conforme demonstrado na Tabela 2.

Tabela 2. Palavras que formam o acrônico "C.H.A.V.E.S."

\begin{tabular}{|c|c|c|c|}
\hline Competência & Características pessoais e profissionais & Impacto & Acrônimo \\
\hline Conhecimento & $\begin{array}{l}\text { Protege o indivíduo enquanto pessoa social como parte da } \\
\text { sociedade. } \\
\text { Garante enquanto profissional seu lugar e portanto seu } \\
\text { vínculo empregatício ou empresarial. }\end{array}$ & $\begin{array}{l}\text { Aquele que se não fosse seu parente seria um amigo } \\
\text { ou amiga. } \\
\text { Autoestima, estímulo por ocupar mais } \\
\text { responsabilidade e desenvolver os mais novos. }\end{array}$ & \\
\hline Atitude & $\begin{array}{l}\text { Entender que fazer sempre as mesmas coisas, não mudar o } \\
\text { comportamento e manter-se na "zona de conforto" esperando } \\
\text { resultados diferentes é insanidade. }\end{array}$ & $\begin{array}{l}\text { Buscar nova samizades, aprender o que não sabe e } \\
\text { ensinar o que aprendeu. } \\
\text { Ser proativo, solicito e buscar trabalhar atualizado } \\
\text { com as novas tecnologias. }\end{array}$ & \\
\hline Valores & $\begin{array}{l}\text { Comportamento, postura, buscar priorizar o respeito em } \\
\text { detrimento da violência respeitando a tradição, idioma, } \\
\text { relacionamento familiar. }\end{array}$ & $\begin{array}{l}\text { Elogiar e antes de comentar sobre os maus } \\
\text { resultados, entender o que aconteceu. } \\
\text { Não aceitar, não produzir ou reproduzir produtos ou } \\
\text { serviços com defeito e acima de tudo não passar para } \\
\text { frente. }\end{array}$ & \\
\hline Ética & $\begin{array}{l}\text { Comportamento. Agir, falar e participar como alguém que } \\
\text { soma e contribui para o que é certo e lícito. } \\
\text { Evitar negligências, imperícias e imprudencia. Ser autentico } \\
\text { quando não saber como executar uma atividade. }\end{array}$ & $\begin{array}{l}\text { Quem participa e colabora para que outros } \\
\text { participem, ensinando e dando exemplo de como e } \\
\text { qual a forma de agir. } \\
\text { Zeloso ao administrar recursos que the foram } \\
\text { confiados. }\end{array}$ & \\
\hline
\end{tabular}

\subsection{Resultado da pesquisa com três perguntas}

O Gráfico 1 apresenta os resultados referente a faixa etária dos 334 indivíduos pesquisados.

Gráfico 1. Faixa etária dos indivíduos pesquisados.

Pergunta 1 - Por favor indique qual a sua faixa etária:

334 respostas

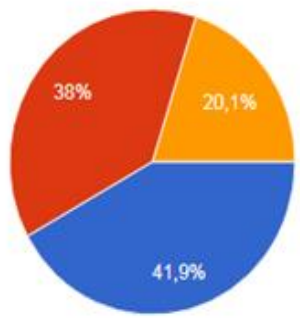

\begin{tabular}{llcc}
20 a 30 anos & Choices & $\%$ & Count \\
- 31 a 49 anos & & & \\
Acima de 50 anos & 20 a 30 anos & $\mathbf{4 1 , 9 2 \%}$ & 140 \\
\cline { 2 - 4 } & 31 a 49 anos & $\mathbf{3 8 , 0 2} \%$ & 127 \\
\cline { 2 - 4 } & Acima de 50 anos & $\mathbf{2 0 , 0 6 \%}$ & 67
\end{tabular}

O Gráfico 2 apresenta os resultados referente a forma como se aprendeu sobre o mapa-múndi, e revela que não houve atualização tecnológica na forma de ensinar, pois a geração mais nova, aprendeu sobre um mapa e não pela tecnologia. 
Gráfico 2 apresenta os resultados referente a faixa etária dos 334 indivíduos pesquisados.

Gráfico 2. Tecnologia usada aprendizagem.

\begin{tabular}{|c|c|c|c|c|}
\hline \multicolumn{5}{|c|}{$\begin{array}{l}\text { Pergunta } 2 \text { - Como você aprendeu sobre o mapa-múndi na sua } \\
\text { alfabetização? }\end{array}$} \\
\hline \multirow[t]{6}{*}{334 respostas } & & Choices & $\%$ & Count \\
\hline & & Opção 1 & $65,27 \%$ & 218 \\
\hline & $\begin{array}{l}- \text { Opçãa } 2 \\
\text { Opcão } 3\end{array}$ & Opçāo 2 & $22,75 \%$ & 76 \\
\hline & - Não me lembro & Opção 3 & $5,39 \%$ & 18 \\
\hline & & Opழ̧วิо 4 & $2,69 \%$ & 9 \\
\hline & & Não me lembro & $3,89 \%$ & 13 \\
\hline
\end{tabular}

O Gráfico 3, apresenta o canal de aprendizado, fato este muitas vezes negligenciado durante o processo de aprendizagem.

Gráfico 3. Canal de aprendizagem.

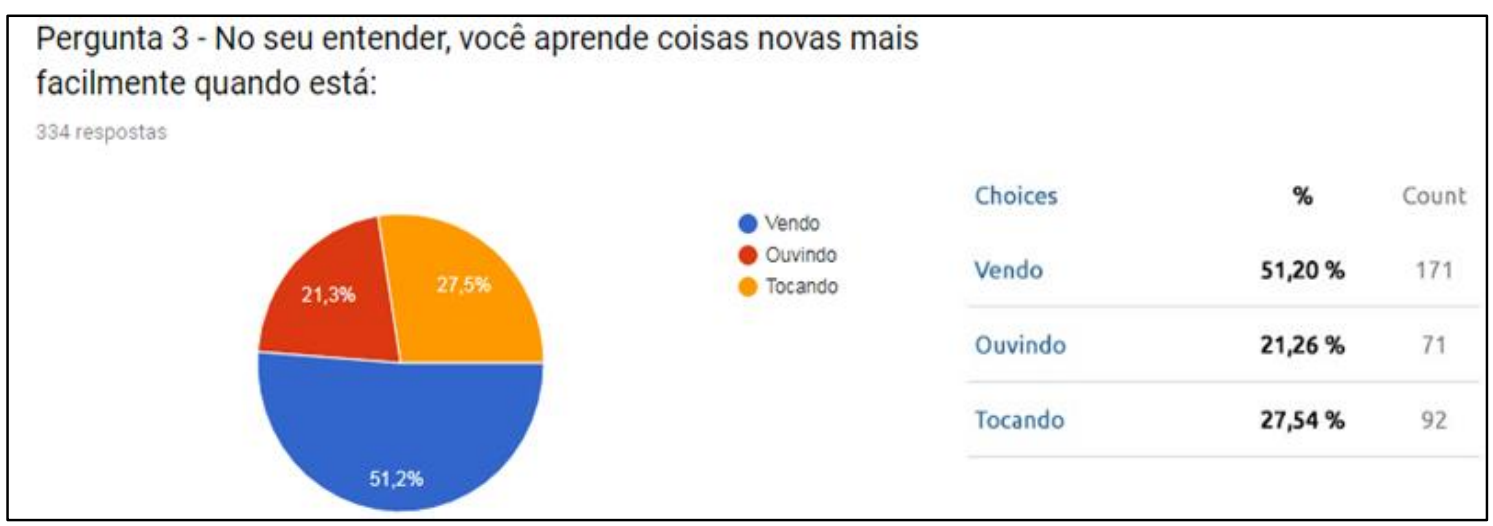

\section{CONCLUSÕES}

Este artigo contribui com apontamentos e sugestões as Instituições de Ensino, pois este trabalho não teve a intenção de esgotar o assunto, mas buscar a continuidade com ferramentas de alinhamento educacional. Assim, o maior desafio das Instituições para as diferentes gerações rumo ao futuro na educação, é a mudança e atualização, favorecendo novas formas de ensinar, avaliar e estimular na expectativa de reter talentos e promover aos egressos a empregabilidade.

Conclui-se pela realidade da falta de planejamento e recursos para ensinar, o que compromete de certa forma, o conhecimento e a habilidade técnica dos alunos, ou seja, quando há um ponto frágil ou vago na cadeia, algo a preencherá, logo onde falta a competência tecnológica, as competências emocionais e sociais devem preencher esse espaço. É sabido que as empresas contratam, treinam e desenvolvem um empregado quase que na mesma proporção que os demitem, principalmente se este empregado não conseguir trabalhar ou ser aceito pelo time de trabalho.

\section{REFERÊNCIAS}


BRASIL. Lei das Diretrizes básicas da Educação brasileira. Lei n. 9394/1996. Disponível em: http://www.planalto.gov.br/ccivil_03/leis/19394.htm. Acesso em 19 mai.2019.

BRASIL. Portaria no 27, de 07 de outubro de 2013, publicado por SEMESP, 9 de outubro de 2013. Ministério da Educação. Disponível em http://www.mec.gov.br. Acesso em 13 mai.2019

CONGER, J. Quem é a geração X? HSM Management, n.11, p.128-138, dez, 1998.

ENGELMANN, D. C. Como lidaremos com a geração Y? 2009. Disponível em: http://www.rh.com.br/Portal/busca.php?btermo=gera\%E7\%E3o+x\&bopcao=1\&btipo=\&bassunto=. Acesso em 19 mai.2019.

FACHIN, O. Fundamentos de metodologia. $3^{\text {a }}$ ed. São Paulo: Saraiva, 2001.

FUSCO, K. Auditivo, visual ou cinestésico: identifique qual é o modo de aprender de seu filho. 2016. Disponível em: http://mdemulher.abril.com.br/familia/auditivovisual-ou-cinestesico-identifiquequal-e-o-modo-do-aprendizado-do-seu-filho/. Acesso em 19 mai.2019.

GAZOLA, A. A. Infográfico: Qual seu estilo de aprendizagem? 2015. Disponível em: http://www.lendo.org/infografico-estilo-aprendizagem-visual-auditivocinestesico/. Acesso em 19 mai.2019.

IBGE. Mapa-múndi: guia de mapas. Disponível em: https://www.guiageo-mapas.com/mapamundi.htm. Acesso em 19 mai.2019.

LEVIN, Jack. Estatística Aplicada a Ciências Humanas. 5a . Ed. Revisada. 2a Reimp. Florianópolis: Editora UFSC, 2004.

LIMA, F. S. De; ZAGO, N. Desafios Conceituais e Tendências Da Evasão No Ensino Superior: a Realidade De Uma Universidade Comunitária. Revista Internacional de Educação Superior, 2018. v. 4, n. 2, p. 366-386.

LOIOLA, R. Geração Y. Revista Galileu. São Paulo, n. 219, p. 50-53, out. 2009.

LOMBARDO, M. M.; EICHINGER, R. W. Competências Lominger. For Your Improvement: A guide for development and coaching. For learners, managers, mentors and feedback givers. $4^{\mathrm{TM}}$ Edition. ISBN 0-974892-3-3. 2006.

LUCKESI, C. Avaliação da aprendizagem: componente do ato pedagógico. Editora Cortez. São Paulo. 2011.

O GLOBO. Portal G1. Disponível em: https://g1.globo.com/educacao/noticia/2019/05/15/entenda-ocorte-de-verba-das-universidades-federais-e-saiba-como-sao-os-orcamentos-das-10-maiores.ghtml. Acesso em 19mai.2019.

OLIVEIRA, S. Geração Y: Era das Conexões, tempo de Relacionamentos. São Paulo: Clube de Autores, 2009. 


\section{ISSN 2447-5378}

PEDREIRA, K. Neurolinguística - Como Definir entre visual, auditivo ou cinestésico. 2014. Disponível em http://supervendedores.com.br/gerencia-de-vendas/lideranca-emotivacao-emvendas/neurolinguistica-como-definir-entre-visual-auditivo-ou-cinestesico/. Acesso em 19 mai.2019.

REIS, T. S., DE SOUZA, G. D. \& DE ROSE, J. C. Avaliação de um programa de leitura e escrita. Estudos em Avaliação Educacional, 20, 425-450. DOI: 10.18222/eae204420092038. 2009.

RESENDE, E. Compreendendo o seu CHA: conheça o perfil de competências, habilidades e aptidões de seu cargo ou profissão. São Paulo: Summus, 2008.

SIDMAN, M. Equivalence relations and the reinforcement contingency. Journal of Experimental Analysis of Behavior,74, 127-146. doi: 10.1901/jeab.2000.74-127. 2000.

STEIN, L. M. TDE - Teste de Desempenho Escolar: manual para aplicação e interpretação. São Paulo: Casa do Psicólogo. 1994.

TRIOLA, Mário F. Introdução à Estatística. 10ª Ed. Belo Horizonte: LTC, 2008.

VELOSO, E. F. R.; DUTRA, J.S.; NAKATA, L. E. Percepção sobre carreiras inteligentes: diferenças entre as gerações Y, X e baby boomers. 2011.

ZANOTTO, M. L. B. Formação de professores: a contribuição da análise do comportamento. São Paulo: Educ. 2002.

YONG, H. The design and implement of middle school student's evaluation system with improved AHP [D]. Shandong University. 2013. 